Laser Chem., 1999, Vol. 19, pp. 233-235

Reprints available directly from the publisher Photocopying permitted by license only
(C) 1999 OPA (Overseas Publishers Association) N.V. Published by license under the Harwood Academic Publishers imprint, part of The Gordon and Breach Publishing Group.

\title{
TEMPERATURE INDUCED PROTEIN UNFOLDING AND FOLDING OF RNase A STUDIED BY TIME-RESOLVED INFRARED SPECTROSCOPY
}

\author{
H. GEORG ${ }^{\mathrm{a}}$, C. W. WHARTON ${ }^{\mathrm{b}, *}$ and F. SIEBERT ${ }^{\mathrm{a}}$

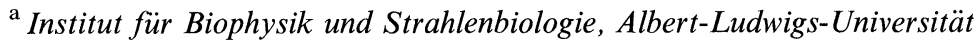 \\ Albertstr. 23, D-79104 Freiburg, Germany; \\ ${ }^{\mathrm{b}}$ School of Biochemistry, University of Birmingham, Edgbaston, \\ Birmingham B152TT, UK
}

(Received 6 April 1997)

\begin{abstract}
When a protein finds its native three-dimensional structure from the unstructured amino-acid chain various processes spanning a large time range are relevant. To understand the mechanism of protein folding one needs to cover the entire folding/ refolding $(\mathrm{U} \leftrightarrow \mathrm{N})$ reaction on a structural level. In the case of RNase $A$, the main structural changes occur in the ms time range, that can be monitored with rapid-scanFTIR spectroscopy combined with rapid mixing techniques. To induce unfolding we inject aqueous protein solution into a hot IR cuvette and record the time course of the spectral changes. A lag phase is found when the unfolding conditions are relatively weak, suggesting an unfolding intermediate.
\end{abstract}

Keywords: Protein folding; time-resolved infrared spectroscopy; RNase A; stopped-flow

Unfolding studies on RNase A revealed three major kinetic phases. In addition to the main unfolding transition (ms) and slow proline isomerization steps (sec. to minutes), a very fast phase has been found by Phillips et al., at $\mathrm{pH}^{*} 5.7$ [1], as well as by our group at $\mathrm{pH}^{*} 2.0$ [2]. Nevertheless, the medium phase seems to comprise the main unfolding transition and will be focused on in this study.

Deuterated Ribonuclease A (RNase A) was heated to defined temperatures and IR absorption spectra were recorded (insert in Fig. 1).

*Corresponding author. 


\section{Unfolding spectrum of RNase $\mathrm{A}$ in $\mathrm{D}_{2} \mathrm{O}$}

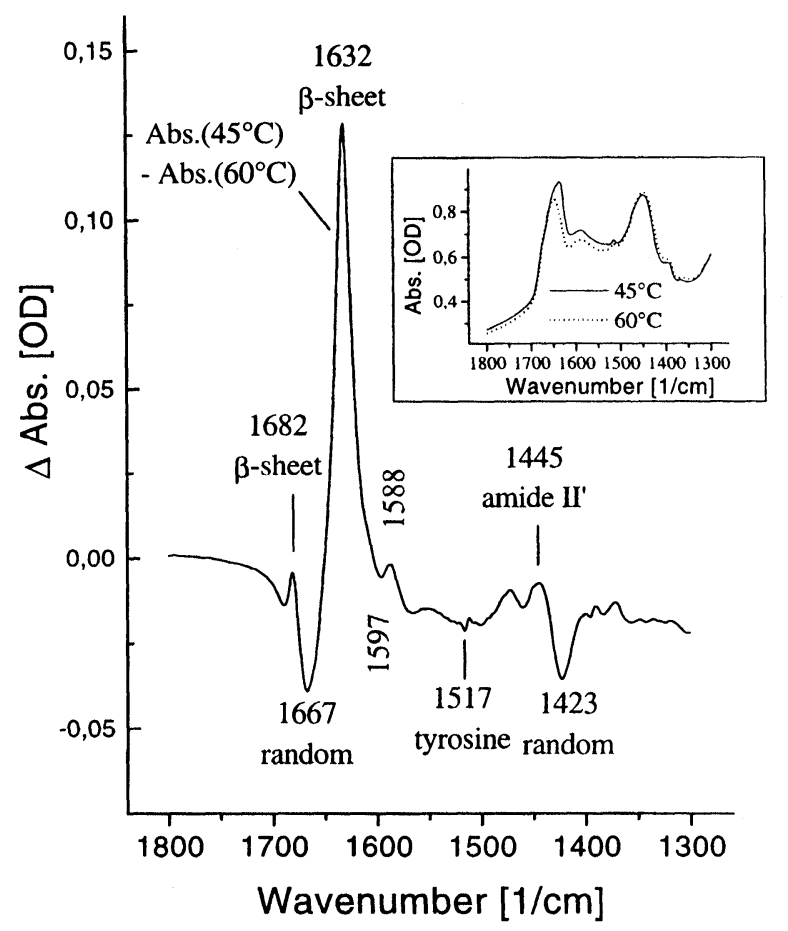

FIGURE 1 Temperature dependent IR absorption difference of $1 \mathrm{mM}$ RNase A at $\mathrm{pH}^{*} 3.9, \Delta$ Abs. $=\mathrm{Abs} .\left(45^{\circ} \mathrm{C}\right)-\mathrm{Abs} .\left(60^{\circ} \mathrm{C}\right)$; insert: IR absorption spectra at $45^{\circ} \mathrm{C}$ (solid line) and at $60^{\circ} \mathrm{C}$ (dotted line).

The calculated absorption difference is shown in Figure 1 and shows the assignment of distinct absorption bands to structural elements of RNase A. Injecting the native protein at $25^{\circ} \mathrm{C}$ by a stopped-flow apparatus into a hot $\left(T_{\text {final }}=56(50)^{\circ} \mathrm{C}\right)$ IR-cuvette, a ms temperature jump is generated inducing the unfolding of the protein [3]. Rapidscan-FTIR spectra are recorded every $16 \mathrm{~ms}$. By rearranging the data the kinetic response of RNase A can be extracted for any wavenumber of interest. Figure 2 shows the unfolding kinetic under strong $\left(T_{\text {final }}=56^{\circ} \mathrm{C}\right)$ or weak $\left(T_{\text {final }}=50^{\circ} \mathrm{C}\right)$ unfolding conditions at $1632 \mathrm{~cm}^{-1}$ and $1667 \mathrm{~cm}^{-1}$, representing the decay of $\beta$-sheet structure and the growth of "random" structure, respectively. Under the weak 
Unfolding of RNase A ( $\left.1 \mathrm{mM}, \mathrm{D}_{2} \mathrm{O}\right)$

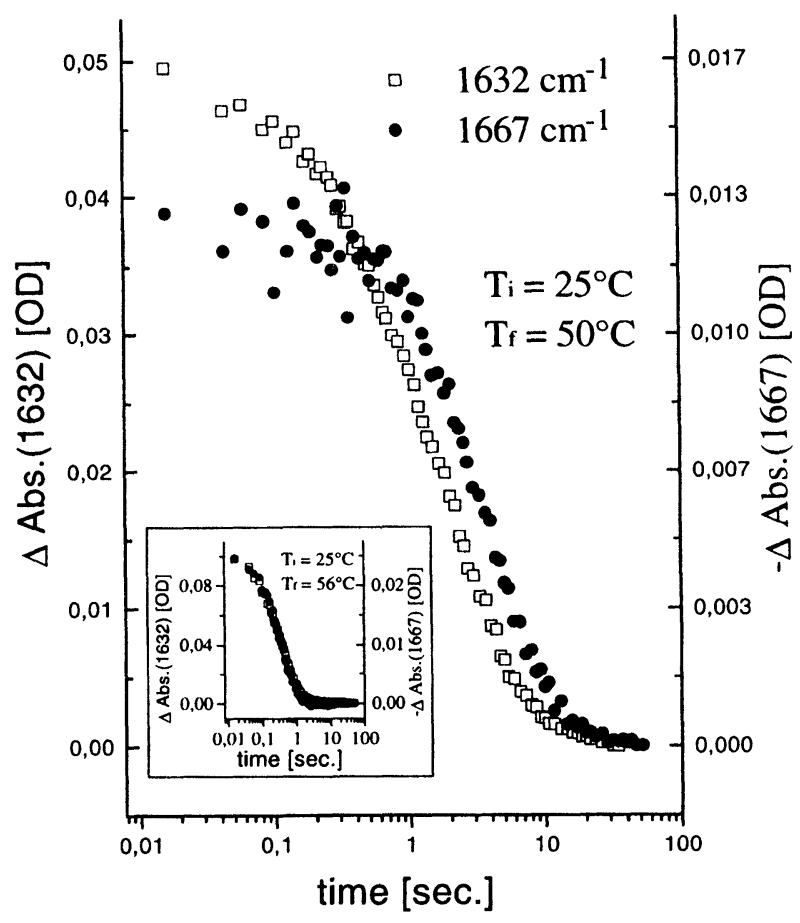

FIGURE 2 Temperature jump induced IR absorption changes of $1 \mathrm{mM}$ RNase A at $\mathrm{pH}^{*} 3.9$ for $1632 \mathrm{~cm}^{-1}$ (open squares) and $1667 \mathrm{~cm}^{-1}$ (filled circles) and a final temperature of $50^{\circ} \mathrm{C}$; insert: Final temperature of $56^{\circ} \mathrm{C}$.

unfolding condition the growth of the "random" structure relative to the decay of the $\beta$-sheet structure suggests an intermediate that accumulates under these conditions.

\section{References}

[1] Phillips, C. M., Mizutani, Y. and Hochstrasser, R. M. (1995). Proc. Natl. Acad. Sci., USA 92, pp. 7292-7296.

[2] Georg, H. and Siebert, F. (1995). Temperature-pulse induced protein unfolding and folding studied by time-resolved Infrared spectroscopy, Conference proceedings of TRVS 7.

[3] White, A. J., Drabble, K. and Wharton, C. W. (1995). A stopped-flow apparatus for infrared spectroscopy of aqueous solutions, Biochemical Journal, 306, 843-849. 